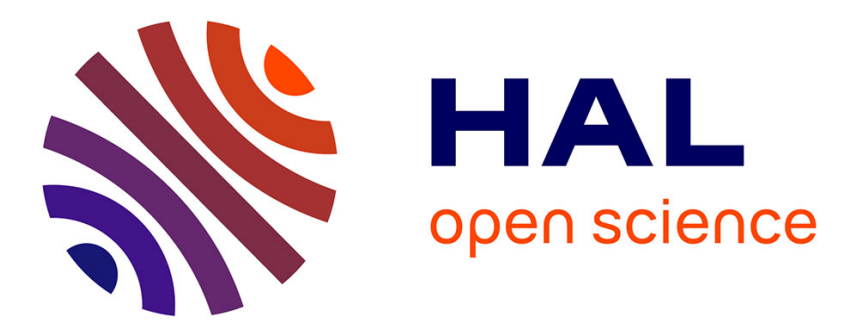

\title{
Space Charge in Electron-Beam Irradiated Cross- Linked Polyethylene (XLPE): Charge Implantation and Release from the Bulk
}

C. Mouchache, Virginie Griseri, N. Saidi-Amroun, G. Teyssedre, S. Mouaci, M. Saidi

\section{To cite this version:}

C. Mouchache, Virginie Griseri, N. Saidi-Amroun, G. Teyssedre, S. Mouaci, et al.. Space Charge in Electron-Beam Irradiated Cross- Linked Polyethylene (XLPE): Charge Implantation and Release from the Bulk. 2019 IEEE Conference on Electrical Insulation and Dielectric Phenomena (CEIDP), Oct 2019, Richland, United States. pp.482-485, 10.1109/CEIDP47102.2019.9009902 . hal-03003956

\section{HAL Id: hal-03003956 https://hal.science/hal-03003956}

Submitted on 13 Nov 2020

HAL is a multi-disciplinary open access archive for the deposit and dissemination of scientific research documents, whether they are published or not. The documents may come from teaching and research institutions in France or abroad, or from public or private research centers.
L'archive ouverte pluridisciplinaire HAL, est destinée au dépôt et à la diffusion de documents scientifiques de niveau recherche, publiés ou non, émanant des établissements d'enseignement et de recherche français ou étrangers, des laboratoires publics ou privés. 


\title{
Space Charge in Electron-Beam Irradiated Cross- Linked Polyethylene (XLPE): Charge Implantation and Release from the Bulk
}

\author{
${ }^{1} \mathrm{C}$. Mouchache, ${ }^{2}$ V.Griseri, ${ }^{1}$ N.Saidi-Amroun, ${ }^{2}$ G. Teyssèdre, ${ }^{1}$ S. Mouaci and ${ }^{1}$ M. Saidi \\ ${ }^{1}$ Material Physics Laboratory, Physics Faculty, University of Sciences and Technology (USTHB) \\ BP 32 El-Alia, Bab-Ezzouar, Algiers, Algeria, \\ ${ }^{2}$ LAPLACE, Université de Toulouse and CNRS, 118 Route de Narbonne, 31062 Toulouse Cedex 9, France.
}

\begin{abstract}
The aim of the present work is to study the dynamics of the space charge in crosslinked polyethylene (XLPE) induced by electron beam irradiation. For this purpose three energies have been chosen so as to implant charges in a controlled way, in the volume, at different depths not too close to the electrodes. Pulsed Electro Acoustic (PEA) method was used to measure space charge in each sample, at the end of the irradiation process, in ambient conditions. The space charge measurements show the existence of two electron implantation sites after irradiation, one in the bulk at a depth depending on the irradiation energy and the other near the irradiated surface and a fixed position $(25 \mu \mathrm{m})$. The application of the electric field shows that the charge implanted in the volume tends to be evacuated during the polarization. The charge accumulated persists during the relaxation and is stable after 1 hour. The current measurements reveal the impact of the irradiation in XLPE sample: the steady current measured on the irradiated sample is substantially higher compared to the one recorded on the non-irradiated specimens. Also a change in conduction mechanism is observed. The current recorded on XLPE irradiated weakly diverges from linearity with the electric field in the field range up to $40 \mathrm{kV} / \mathrm{mm}$.
\end{abstract}

\section{INTRODUCTION}

Cross-linked polyethylene (XLPE) is one of the most used electrical polymeric insulation for DC power cables for its good electrical and thermal properties. The issues with the presence of space charge in XLPE have led to a large amount of research $[1,2]$ into the way to study the electric behavior and the way to improve material compounding. Space charge plays an important role in aging of XLPE and strongly affects its electrical characteristic [3], therefore the behavior and the dynamic of apparition and accumulation is continuously investigated. When XLPE is submitted to a high DC field a space charge is developed in the bulk. However, many processes can be involved in charge accumulation and unravelling their nature is tricky.

An electron beam represents an alternative ways to build up a space charge in insulating materials, as reported using a recently built irradiation means $[4,5]$. The irradiation by electrons allowed to deposit charges at specific location, and to control the quantity of deposited charge with varying the beam current or the time specimen is exposed to irradiation.
This constitutes a marked difference compared to charge implantation with DC field.

In this study of space charges in XLPE, electronic charges where deposited at different depths using an electron beam. We focus on charges deposited in the bulk of XLPE materials. To probe the distribution and the dynamic of charge implanted in the bulk after the irradiations and during the polarisation under dc field, the pulsed electro-pulsed acoustic (PEA) method has been chosen. Isothermal charging current measurements on XLPE have been done using different electric field levels up to $40 \mathrm{kV} / \mathrm{mm}$ at different temperatures. Experimental results were used to determine the mechanism of conduction on both irradiated and non-irradiated sample and evaluate the difference induced by the irradiation.

\section{EXPERIMENTAL SET-UP}

\section{A. XLPE Samples}

The specimens were taken from rolls issued from peeled HV cable produced in the frame of the European project Artemis $[6,7]$. The cable peelings were $150 \mu \mathrm{m}$ in thickness and $80 \mathrm{~mm}$ wide. Prior to peeling, the cable, with $15 \mathrm{~mm}$ thick insulation, was submitted to an electrical and thermal aging under $225 \mathrm{kVac}$ voltage with $90^{\circ} \mathrm{C}$ at the inner screen. More information on samples and peelings are available elsewhere [7]. Electrical and structural characterizations of the aged cable were achieved in a previous work and it was considered that the induced ageing is negligible [8].

The sample was irradiated with an electron beam using irradiation chamber called Matspace, which is equipped with an electron gun with energy in the range [10-100 keV] [9]. The irradiation was performed under vacuum of about $10^{-6}$ mbar, we can consider that the irradiation to be homogeneous on the sample, with a flux of $1 \mathrm{nA} / \mathrm{cm}^{2}$. The irradiation time was limited to 5 minutes to avoid surface discharges.

\section{B. Space charge measurements}

Space charge measurements were performed by classic pulsed electro acoustic (PEA) $[10,11]$ method. The test bench is based on a PEA cell developed in the Laboratory. This technique is currently used to measure the distribution of the charge in solid dielectric materials.

The specimen was placed between a semiconducting material layer (carbon black doped polymer) acting as high 
voltage electrode and an aluminum bottom electrode to the ground. The measurements were carried out under dc field of $40 \mathrm{kV} / \mathrm{mm}$ in air at a controlled temperature of $25^{\circ} \mathrm{C}$. The polarization was applied to all samples for $10000 \mathrm{~s}$ with a depolarization time of $3600 \mathrm{~s}$. The space charge profile was not recorded during the application ramp at $1 \mathrm{kV} / \mathrm{mm} . \mathrm{s}^{-1}$ for electric field to reach the desired voltage.

\section{Current measurements}

The charging current measurements were performed in air at different temperature ranging from 20 to $80{ }^{\circ} \mathrm{C}$ by step of $20{ }^{\circ} \mathrm{C}$, with a various DC voltage varying from 5 to $40 \mathrm{kV} / \mathrm{mm}$ for each temperature. Gold electrodes of $20 \mathrm{~mm}$ diameter and $30 \mathrm{~nm}$ thickness were deposited on both faces of the samples. The sample was then placed between two brass electrodes for the measurements. The protocol used in the measurements consisted of $10000 \mathrm{~s}$ of polarization and a depolarization time lasting $3600 \mathrm{~s}$.

\section{RESULTS AND DISCUSSION}

\section{A. Charge implantation profiles}

Fig. 1 shows space charge distributions obtained in air just after the electronic irradiation in XLPE, with different irradiation energies of 60,70 and $80 \mathrm{keV}$. Peaks detected on the electrodes (abscissa 0 and $150 \mu \mathrm{m}$ ) represent the image charges. As we can see, a broad negative charge peak is detected in the bulk at different depth as function of the energy of electrons. For the irradiation with $60 \mathrm{keV}$ the peak maximum is observed at $65 \mu \mathrm{m}$ from the irradiated surface. With the increase of the energy to $70 \mathrm{keV}$ the electrons penetrate deeper, the peak maximum being detected at $80 \mu \mathrm{m}$. After the irradiation under $80 \mathrm{keV}$ the peak is observed at about $100 \mu \mathrm{m}$. The profile for the irradiation under $80 \mathrm{keV}$ is with a shoulder near the ground electrode.

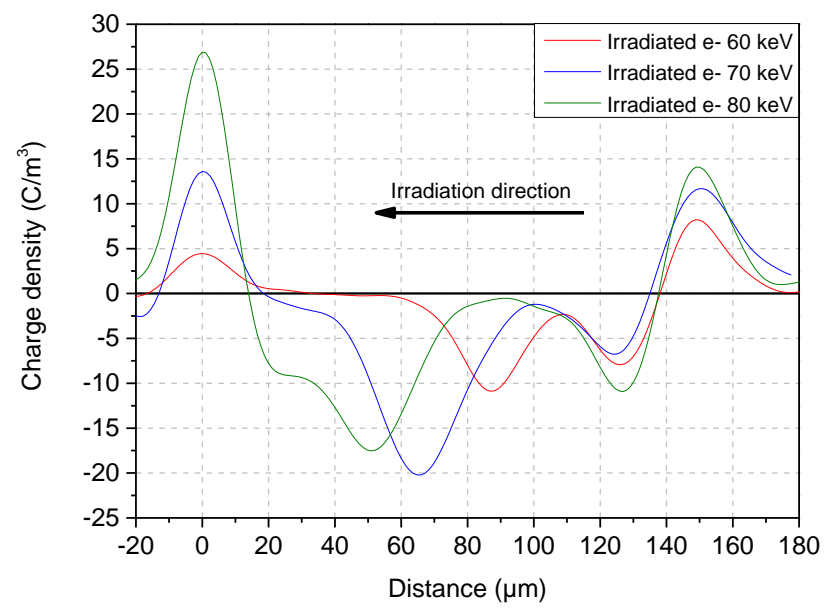

Fig. 1. Space charge profiles recorded on a XLPE after irradiation under 60, 70 and $80 \mathrm{keV}$ electron beam for 5 min with a flux of $1 \mathrm{nA} / \mathrm{cm}^{2}$. The film surfaces are at 0 and $150 \mu \mathrm{m}$.

It gives the impression that some charges have drifted to the ground electrode during or after thermalization. During irradiation, one of the faces of the sample is at floating potential. As a result, a high field region settles between the region of implanted charges and the ground electrode, and this space-charge induced field is higher as the charge region is close to the ground. This feature main explain the drift of negative charges for the highest electron beam energy used here.

On the other hand a negative charge is detected near to the surface where the maximum of the peak observed at $25 \mu \mathrm{m}$. This deposited charge its common for all irradiations used. The presence of this unexpected charge near the surface is still not clearly understood. It could correspond to drift back of implanted electrons, to artefacts in the irradiation chamber producing low energy electrons, or to an evolution of the surface of the films during their storage time.

\section{B. Space charges under DC fields}

The measurements of space charge on non-irradiated XLPE performed under polarization using DC field of $40 \mathrm{kV} / \mathrm{mm}$ for 1 hour is shown in Fig. 2. Negative charge injection appears clearly from the ground electrode. Over time the negative charge grows slowly and the image charge on the ground electrode decreases. Also the injection of a small amount of positive charges near to the anode is detected, but without evolving much with time.

The space charge profiles obtained in Volts-off for $1 \mathrm{~h}$ are plotted in Fig. 2. The negative charges injected during the polarization step appear spread nearly homogeneously into the all insulation. The charge decays uniformly with time. The positive induced charges on the electrodes representing the image charge are also decreasing slowly during the relaxation. In the last profile recorded after 1 hour of relaxation a negligible amount of negative charges is still detected in the volume, and we can consider that the charges are totally recombined or extracted.

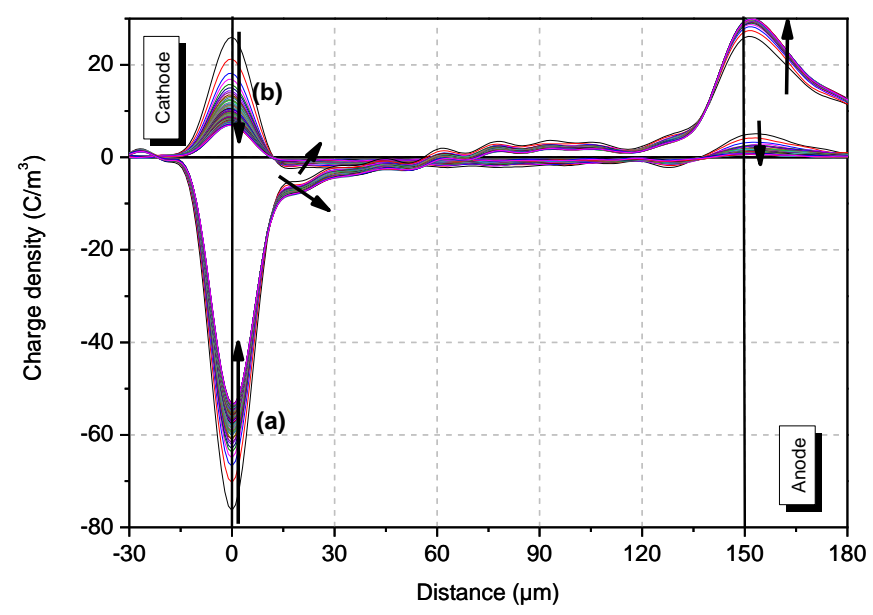

Fig. 2. Space charge profile recorded on a non-irradiated XLPE, during (a) $1 \mathrm{~h}$ of polarisation under $40 \mathrm{kV} / \mathrm{mm}$ and (b) $1 \mathrm{~h}$ of relaxation in Volt-off. Arrows indicate the trend regarding charge evolution in time.

During polarization of the sample irradiated under $70 \mathrm{keV}$, Fig. 3, the distribution of the space charge shows much change 
in the $3 \mathrm{~h}$ charging time. Indeed, the charge previously stored starts to decrease as soon as the field is applied. The initial peak vanishes after about $1 \mathrm{~h}$ of polarization. At the same time an accumulation of negative charge near to the irradiated surface (at $25 \mu \mathrm{m}$ from it) is detected. This accumulation of negative is added to previously stored negative charge at this depth.

Once the initial peak has completely disappeared, a prominent positive charge peak appears at 50 to $120 \mu \mathrm{m}$ from the ground electrode. The peak maximum is observed at about $75 \mu \mathrm{m}$; the peak grows continuously during the polarization. The influence charges on both electrodes are also changing continuously during the polarization due to internal charges redistribution. A small amount of positive heterocharge is detected in the non-irradiated region.

During electron-beam irradiation primary electrons are deposited and electron-hole pairs are created due to the energy deposition. In fact the density of electron-hole pairs creation is theoretically much higher than primary electrons deposition, the energy amount to create a pair being taken as $30 \mathrm{eV}$ [12]. Most of the pairs created presumably disappear by geminate recombination but some of them lead to charge trapping with a zero net charge as long as the charges don't move. With the application of a DC field, redistribution of the charges appears and net positive charges can be revealed. In the configuration used for applying the field, electrons are drifted towards the right electrode, i.e. in the irradiated region and positive charges to the non-irradiated region. As transport is most effective in the irradiated region, negative charges tend to be extracted at the anode or trapped nearby it whereas positive charges do not move substantially. This leads to the build-up of a net positive charge.

During Volt-off, Fig. 4, it is obvious that the positive charge created when the DC field is applied decreases very slowly. The same behavior holds for the net charge peaks near cathode and anode. The distribution of space charge during relaxation is same as in the last profile observed during polarization. An electrostatic equilibrium seems to be reached between the different kinds of charges. Results for different e-beam energy, not shown here for the sake of space saving show similar trends, i.e. change of the sign of the charge from negative to positive followed by stable charge in volts-off.

\section{Charging current}

Charging currents were measured for about 10000s under DC field of $40 \mathrm{kV} / \mathrm{mm}$ at a temperature of $20^{\circ} \mathrm{C}$. The charging current recorded is plotted on Fig. 5, for both irradiated under $70 \mathrm{keV}$ and non-irradiated samples. Just after voltage application, a fast decrease in current is observed (Fig. 5) in the non-irradiated sample tending to a stable value after about 4000 s. For the irradiated specimen the current deceases continuously over the $3 \mathrm{~h}$ charging time, and it seems not reaching a steady state value. Because of this strong difference in transient currents, there is a crossover of the curves, the final current being higher for the irradiated material.

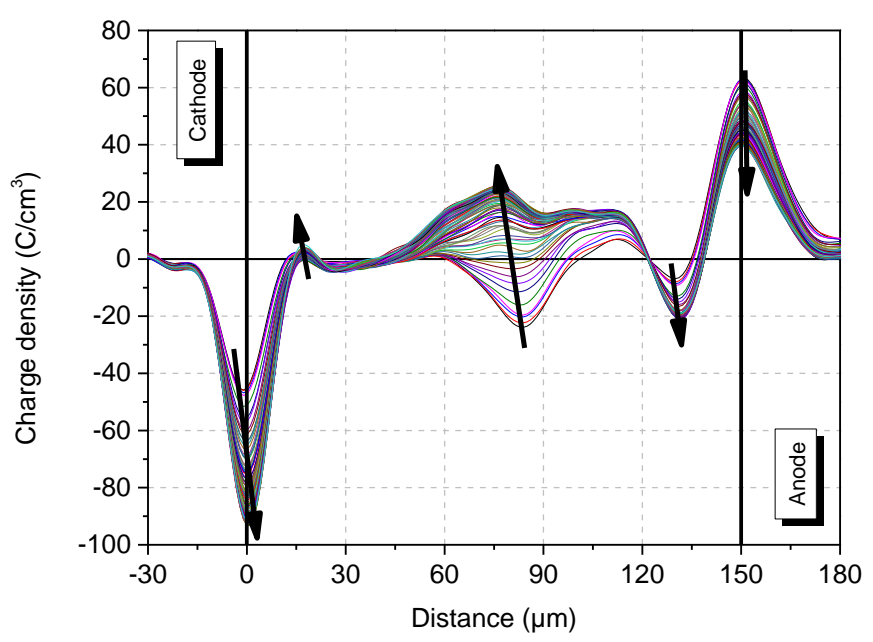

Fig. 3. Space charge profile recorded on a XLPE, after irradiation by electrons under $70 \mathrm{keV}$ for $5 \mathrm{~min}$. during $3 \mathrm{~h}$ of polarization under $40 \mathrm{kV} / \mathrm{mm}$. Irradiated face to the right.

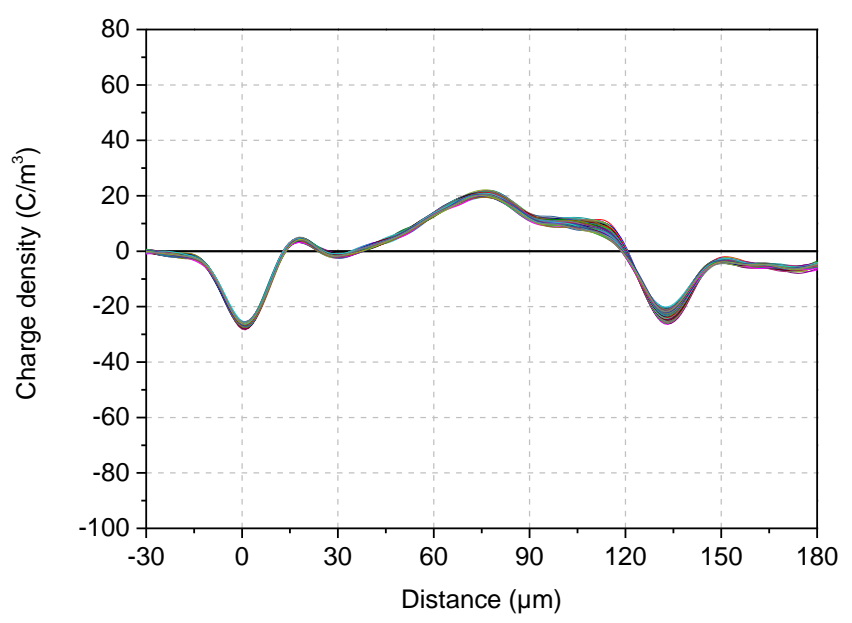

Fig. 4. Space charge profiles recorded on a XLPE irradiated by electrons under $70 \mathrm{keV}$ for $5 \mathrm{~min}$, during $1 \mathrm{~h}$ of relaxation after polarization for $3 \mathrm{~h}$ under $40 \mathrm{kV} / \mathrm{mm}$.

In these experiments, currents were measured consecutively at different field steps followed by discharging (see below). The presence of slowly moving charges inside the irradiated sample certainly brings complex response when submitted to step voltages followed by discharging.

Fig. 6 shows the evolution of current density vs. electric field at a temperature of $20^{\circ} \mathrm{C}$ for irradiated and non-irradiated XLPE. The values of current are taken after $3 \mathrm{~h}$ of polarization for each sample (even though the charging current is still decreasing). Between each polarization step the specimen was short-circuited for about $1 \mathrm{~h}$. A linear fitting was applied in order to the determine the dominating regime of conduction.

In non-irradiated XLPE sample we find two linear regions; the intersection of these lines defines a threshold field [13] between two conduction regimes at low and high field. The threshold field is at $20 \mathrm{kV} / \mathrm{mm}$. The slope at low field is about 1.4. We consider that the conduction is dominated by ohmic mechanism. At high field the slope is estimated to be equal to 
3.6 which is indicative of conduction process governed by space charge limited current.

The current density vs. electric field characteristic on the irradiated XLPE is very different from that of the reference sample. A much slower field dependence of the current appears, with a slope of 0.65 and no transition of mechanism is detected. The current here is modified by the presence of internal charges generated by irradiation. The highest value of current density at $5 \mathrm{kV} / \mathrm{mm}$ compared to the one at $10 \mathrm{kV} / \mathrm{mm}$, can be explained by the transport of charge deposited by the electron beam encompassing excess electrons deposited as well as electronic or ionic carriers created upon energy deposition.

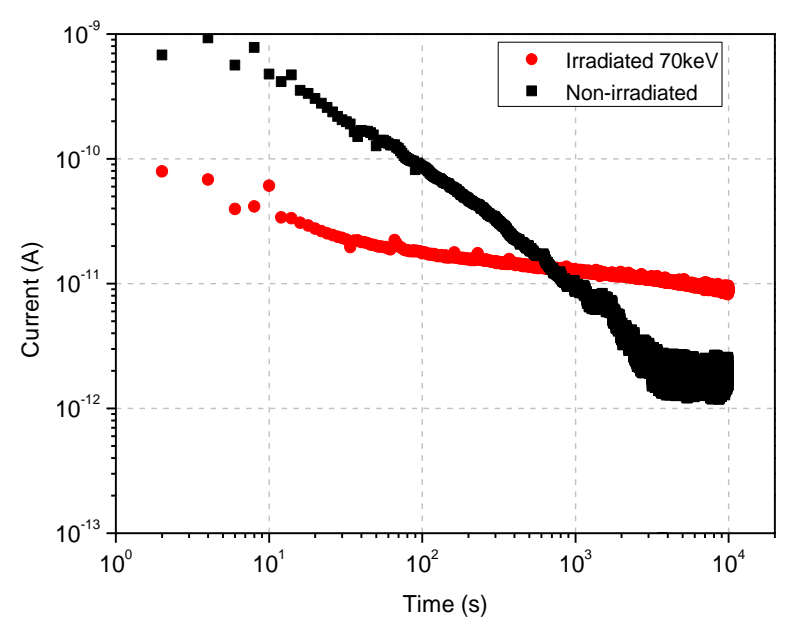

Fig. 5. Charging current measured in $10000 \mathrm{~s}$ at $20^{\circ} \mathrm{C}$ and $40 \mathrm{kV} / \mathrm{cm}$ for nonirradiated and irradiated $70 \mathrm{keV}$ XLPE.

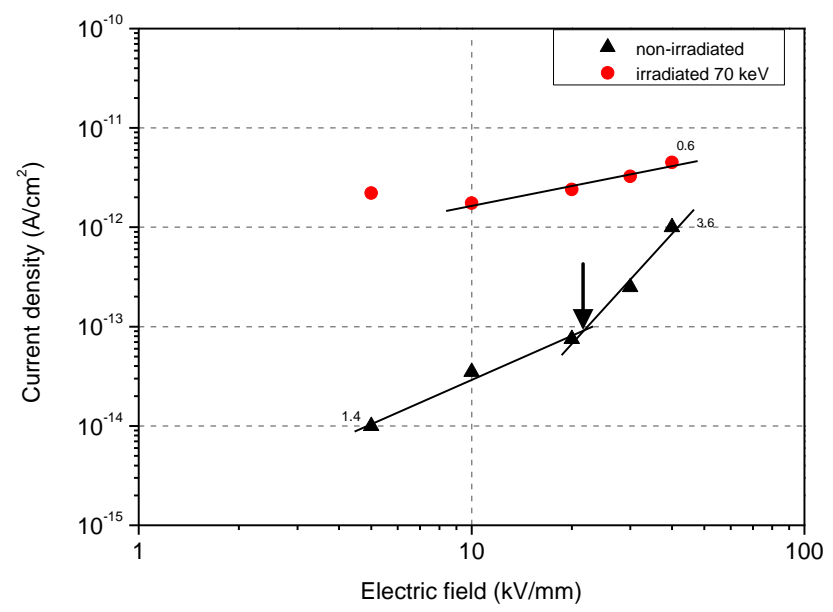

Fig. 6. Current density as function of electric field in log-log scale for non irradiated and $70 \mathrm{keV}$ irradiated XLPE at $20^{\circ} \mathrm{C}$

\section{CONCLUSION}

Two charge clouds have been observed in XLPE peelings during and after e-beam irradiation. One of the charge clouds appears in the bulk and corresponds to primary electron deposition. The second one is near the irradiated face; the charge appears very stable there. Several reasons may explain this feature: either positive charges are accumulated during polarisation and persist during relaxation or traps are formed near the surface during long-term storage of cable peelings or blocking conditions are at play for charge release. Current transients and current-field characteristics show that the electrical properties are substantially influenced by the irradiation process. It is obvious that application of DC field for $1 \mathrm{~h}$ did not erase the history of the samples regarding irradiation effects. The open question is whether only electrostatic effects are at play during irradiation or should we consider an evolution of the trapping and transport sites, i.e. chemical evolution of the material. This will be investigated in the next steps.

\section{ACKNOWLEDGMENT}

The work is supported by French-Algerian Tassili research program in the frame of Partenariat Hubert Curien (PHC).

\section{REFERENCES}

[1] G. Teyssedre, C. Laurent, G.C. Montanari, F. Palmieri, A. See, L.A. Dissado, and J.C. Forthergill, "Charge distribution and electroluminescence in cross-linked polyethylene under dc field", $J$. Phys. D, vol. 34, pp. 2830-2844, 2001.

[2] D. He, X. Wang, H. Liu, Q. Li, and G. Teyssèdre, "Space charge behavior in XLPE cable insulation under ac stress and its relation to thermo-electrical aging", IEEE Trans. Dielectr. Electr. Insul., vol. 25, pp. 541-550, 2018.

[3] Y. Zhang, J. Lewiner, C. Alquié, and N. Hampton, "Evidence of strong correlation between space-charge buildup and breakdown in cable insulation," IEEE Trans. Dielectr. Electr. Insul., vol. 3, pp. 778-783, 1996.

[4] V. Griseri, P. Malaval, L. Berquez, T.A. Tung, S. Le Roy, L. Boudou and A. Boulanger, "Charge build-up and transport in electron beam irradiated polymers in a new irradiation chamber", Proc. IEEE-CEIDP, pp. $688-691,2010$

[5] M. E. Banda, V. Griseri, G. Teyssèdre and S. Le Roy, "Polarization of electron-beam irradiated LDPE films: contribution to charge generation and transport", J. Phys. D, vol. 51, p. 155303, 2018.

[6] J. C. Fothergill et al., "Electrical, microstructural, physical and chemical characterization of HV XLPE cable peelings for an electrical aging diagnostic data base", IEEE Trans. Dielectr. Electr. Insul., vol. 10, pp. 514-527, 2003

[7] G. Teyssedre, C. Laurent and G.C. Montanari, "Semi-quantitative analysis of photoluminescence in thermoelectrically aged cables: IIAnalysis of a population of cables", IEEE Trans. Dielectr. Electr. Insul., vol. 16, pp. 1189-1198, 2009.

[8] V. Griseri, G. Teyssedre, N. Saidi-Amroun, S. Mouaci, C. Mouchache, and M. Saidi, "Dynamic of space charge in electron-beam irradiated cross-linked polyethylene". Proc. IEEE-ICD, pp. 601-604, 2018

[9] V. Griseri, X.T. Nguyen, and L. Berquez, "Analysis of the Pulsed Electroacoustic signal treatment recorded on electron beam irradiated dielectrics", J. Electrostatics, vol. 71, pp. 422-428, 2013.

[10] T. Maeno, T. Futami, H. Kushibe, T. Takada and C. M. Cooke, "Measurement of spatial charge distribution in thick dielectrics using the Pulsed Electroacoustic method", IEEE Trans. Electr. Insul., vol. 23, pp. 433-439, 1988.

[11] Y. Li, M. Masuda and T. Takada, "Pulsed Electroacoustic method for measurement of charge for accumulation in solid dielectrics" IEEE Trans. Dielectr. Electr. Insul., vol. 1 pp. 188-195, 1994.

[12] G.M. Sessler, M.T. de Figueiredo, and G.F. Leal Ferreira, "Models of charge transport in electron-beam irradiated insulators", IEEE Trans. Dielectr. Electr. Insul., vol. 11, pp. 192-202, 2004.

[13] G.C. Montanari and P.H.F. Morshuis, " Space charge phenomenology in polymeric insulating materials", IEEE Trans. Dielectr. Electr. Insul., vol. 12, pp. 754-767, 2005. 
